\title{
Reply to Paik WH and colleague: "Is there any tip to perform EUS-guided drainage easier and safer?"
}

\section{Dear Editor,}

We would like to thank Paik and Park for their letter [1] commenting on our manuscript [2] in which we described the intra-channel stent releasing technique, which was performed in $100 \mathrm{pa}$ tients using a lumen-apposing self-expandable fully covered metal stent mounted on a delivery catheter with an electrocautery wire on the distal tip (ECAxios $^{\mathrm{TM}}$, Boston Scientific Corp., Marlborough, MA, United States). With our technique, the proximal flange of the stent is released under endoscopic ultrasound (EUS) guidance in the working channel of the echoendoscope, without fluoroscopy, and the complete release of the stent is achieved by gently pulling back the scope. This allows maintenance of a stable position without the need to detach the scope from the wall of the gastrointestinal tract where the procedure is performed. Paik et al. [3] described a similar technique for performing hepaticogastrostomy, a procedure in which maintenance of a stable position is difficult especially during release of the stent. In their "modified stent deployment maneuver", after deploying the distal portion of the stent, the remainder of the stent is also released within the channel of the echoendoscope, as in our study, before obtaining transgastric stent placement by slowly pulling back the echoendoscope. All of the procedure is done under fluoroscopic guidance.

Paik et al. [3] pointed out the importance of the use of fluoroscopy during their procedure and recommended using it for all EUS-choledochoduodenostomy procedures as well. The stent we used has been designed to be extremely visible under EUS guidance, thus making EUS-guided stent release a very reliable and safe procedure, as shown by our study. Moreover, we also stressed that the procedure should be performed in a fluoroscopy room so as to have fluoroscopy available if required. Finally, we believe that releasing the stent under endoscopic view following visualization of the black marker on the delivering catheter is also important so as to have different options, which can be used in different clinical scenarios. Training should allow users of this device to perform EUS-guided stent release using different techniques, which can be of value when facing different situations. The potential for EUS-guided drainage procedures is huge, but it needs to be associated with the development of dedicated accessories, and standardization of the techniques, and should be evidence-driven to bring it to another level.

\section{Competing interests}

None

The authors

Andrea Anderloni ${ }^{1}$, Fabia Attili ${ }^{2}$, Silvia Carrara ${ }^{1}$, Domenico Galasso ${ }^{2,3}$, Milena Di Leo ${ }^{1}$, Guido Costamagna ${ }^{2}$, Alessandro Repici $^{1,4}$, Rastislav Kunda ${ }^{5}$, Alberto Larghi ${ }^{2}$

1 Department of Gastroenterology, Digestive Endoscopy Unit, Humanitas Research Hospital, Rozzano, Italy

2 Digestive Endoscopy Unit, Catholic University, Rome, Italy
3 Division of Gastroenterology, Department of Internal Medicine, Riviera-Chablais, Monthey, Switzerland

4 Humanitas University, Rozzano, Italy

5 Department of Surgical Gastroenterology, Aarhus University Hospital, Aarhus, Denmark

Corresponding author

\section{Andrea Anderloni, MD PhD}

Digestive Endoscopy Unit, Division of Gastroenterology, Humanitas Research Hospital, Rozzano, MI, Italy Fax: +39-02-82247308

andrea.anderloni@humanitas.it

\section{References}

[1] Paik WH, Park DH. Is there any tip to perform EUS-guided drainage easier and safer? Endosc Int Open 2017; 05: 985

[2] Anderloni A, Attili F, Carrara S et al. Intrachannel stent release technique for fluoroless endoscopic ultrasound-guided lumenapposing metal stent placement: changing the paradigm. Endosc Int Open 2017; 5: E25 - E29

[3] Paik WH, Park DH, Choi JH et al. Simplified fistula dilation technique and modified stent deployment maneuver for EUS-guided hepaticogastrostomy. World J Gastroenterol 2014; 20: 5051 - 5059

\section{Bibliography}

DOI http://dx.doi.org/10.1055/s-0043-113563

Endoscopy International Open 2017; 05: E986

(C) Georg Thieme Verlag KG

Stuttgart · New York

ISSN 2364-3722

\section{()ㅜㅇㅇ $\odot$}

